\title{
POLITICAS E PRÁTICAS DE GESTÃO DE PESSOAS: PECULIARIDADES DE UMA ESTRUTURA ORGANIZACIONAL REMOTA
}

\author{
People management policies and practices: \\ peculiarities of a remote organizational structure
}

Envio 02.09.09 / Aceite 01.12.09

\author{
Nildes Pitombo Leite ${ }^{2}$ \\ Lindolfo Galvão de Albuquerque ${ }^{3}$
}

\section{Resumo}

Este artigo teve como principal objetivo investigar como as especificidades na gestão de pessoas são elucidadas dentro de uma empresa com estrutura organizacional remota, distante de grandes centros urbanos. Caracteriza-se como qualitativo, exploratório, baseado em estudo de caso único, cujo nível proposto de análise é o organizacional. O levantamento de campo envolveu um grupo formado pelos níveis de direção, gerência, profissionais de RH, supervisão e coordenação da Mineração Rio do Norte. Para a coleta dos dados primários, foram realizadas dezenove entrevistas em profundidade e observações nas áreas operacionais; para os secundários, análise de documentos fornecidos pela empresa. Foram utilizadas as técnicas

\footnotetext{
${ }^{1}$ Este trabalho é parte de pesquisa mais ampla, apoiada pela FAPESP.

2 Professora doutora do PPGA da Universidade Nove de Julho (UNINOVE), membro do Grupo de Pesquisas em Gestão Estratégica de Pessoas da Faculdade de Economia, Administração e Contabilidade da Universidade de São Paulo (FEA/USP). E-mail: nildespitombo@consensopg.com.br

3 Professor titular do Departamento de Administração da FEA/USP, coordenador do Programa de Pós-Graduação em Administração da FEA/USP e coordenador do Grupo de Pesquisas em Gestão Estratégica de Pessoas da FEA/USP. E-mail: Igdalbuq@usp.br
} 
de análises de conteúdo, documental e a metodologia reflexiva. A fundamentação teórica contemplou quatro temas, dos quais foram extraídas as categorias de análise, consideradas por Vergara (2005), como oriundas de grade fechada. Seus resultados demonstram que as políticas e práticas específicas de gestão de pessoas favorecem a criação de uma cultura de contribuição, desenvolvimento e solidariedade nas relações entre as pessoas. Os gestores exercem influência direta no comprometimento organizacional, permitindo que os valores e a identidade organizacional sejam compartilhados por todos, dentro e fora do contexto de trabalho.

Palavras-chave: Gestão Estratégica de Pessoas; Comprometimento Organizacional; Estrutura Organizacional Remota.

\begin{abstract}
This article has as main objective to investigate how the particularities in people management are elucidated in a company with remote organizational structure, far from urban centers. It is characterized as qualitative, exploratory, based on single case study, with the organizational proposed level of analysis. The survey involved a group formed by the levels of leadership, management, HR professionals, supervision and coordination of Mining Rio do Norte. To collect the primary data were taken nineteen in-depth interviews and observations in the operational áreas; for the secondary data, were taken analysis of documents provided by the company. We used the techniques of content analysis, document and reflexive methodology. The theoretical issues addressed four themes, of which were extracted the categories of analysis, considered by Vergara (2005), as derived from grid closed. Their results show that the specific policies and practices of personnel management help to create a culture of contribution, development and solidarity in the relations between people. Managers exert direct influence on organizational commitment; allowing values and organizational identity are shared by everyone inside and outside the workplace.
\end{abstract} Structure.

Keywords: Strategic Management of People; Organizational Commitment; Remote Organizational

\title{
1 Introdução
}

O que significa questionar as organizações acerca de aonde querem chegar? Definir a gestão que querem construir? Realizar visão, missão, objetivos e metas?

Todo esse conjunto de questões implica: a necessidade de escolha de estruturas, tecnologias e estratégias; o reconhecimento da relevância de compartilhamento de visão, missão, objetivos, metas, estruturas, tecnologias e estratégias; obtenção de comprometimento organizacional como fruto desse compartilhamento.

Enumerados por Salancik (1977), três elementos são fundamentais para gerar comprometimento organizacional baseado em vínculos favoráveis à cooperação que, por sua vez, facilitem a gestão de pessoas nas organizações: a volição, a visibilidade e a irreversibilidade das ações. Esses elementos contêm sentimento e responsabilidade para com o curso da ação escolhido.

Compartilhamento, cooperação e colaboração estão imbricados nos temas: comportamento humano, comprometimento organizacional, gestão estratégica de pessoas e cultura organizacional, todos eles ligados diretamente às pessoas. Por seu turno, pessoas necessitam de estruturas para que possam colocar em prática os seus talentos potenciais.

O conceito de estrutura organizacional, enunciado por Vasconcellos e Hemsley (2003), envolve os subsistemas de autoridade, de comunicação e de atividades e sugere que a decisão 
de descentralização da autoridade deve ser tomada considerando os efeitos, tanto das decisões excessivamente centralizadas no topo da hierarquia quanto do excesso de descentralização. Neste artigo, esse conceito está diretamente ligado ao critério de escolha do universo da pesquisa.

Há, com relação à estrutura organizacional, situações em que a empresa cria uma infraestrutura necessária à instalação das pessoas em uma dada região, distante dos grandes centros, para operar suas unidades lá instaladas.

Nessas circunstâncias, denomina-se estrutura organizacional remota, para gerenciar essa infraestrutura, de estrutura organizacional (departamentalização e atribuições). Operacionalmente esse conceito está presente nas organizações. Entretanto, na literatura, ele não é ainda enunciado. O que de mais próximo foi encontrado nas pesquisas bibliográficas refere-se ao trabalho de Owen (apud HEILBRONER, 1996), o qual traz o conceito proposto como o de 'Aldeias de Cooperação'.

Gerir pessoas com base na estratégia de comprometimento e longe da estratégia de controle implica necessidade de mudanças nas responsabilidades individuais, à medida que as condições mudem e, as equipes, não os indivíduos, transformem-se em unidades organizacionais responsáveis pelo desempenho. Tais mudanças redundam em necessidade de: integrar o foco das variáveis das pessoas com o foco nas variáveis da cultura organizacional; desenvolver cultura própria, na qual as equipes estejam comprometidas com o processo transformador, a partir das atitudes e dos comportamentos.

O objetivo deste artigo é, portanto, investigar como as especificidades na gestão de pessoas são elucidadas dentro de uma empresa com estrutura organizacional remota, distante de grandes centros urbanos. A questão de pesquisa para este caso foi enunciada do seguinte modo: como as especificidades na gestão de pessoas são elucidadas dentro da Mineração Rio do Norte, empresa com estrutura organizacional remota, isolada e confinada?

\section{Breve fundamentação teórica}

Esta breve fundamentação teórica teve como objetivo gerar subsídio para o levantamento de campo, bem como auxiliar na discussão dos resultados nele encontrados. Para tal, alguns pressupostos teóricos foram tomados por referência e serviram de base para as categorias de análise aqui estudadas, quais sejam: comportamento organizacional, comprometimento organizacional, gestão estratégica de pessoas e cultura organizacional.

Na medida em que a organização é tomada como o nível de análise deste artigo, o primeiro pressuposto adotado é o de Pereira (2004), o qual sugere que as organizações são sistemas de pessoas, com caráter permanente, que objetivam realizar um propósito e contribuem para que elas tenham um modo de vida, desempenhando uma função social.

Esse conceito, embutido no pressuposto de Pereira, é contemplado na pesquisa de campo, juntamente com o de Vasconcelos (2004), no qual a organização pode ser compreendida como uma entidade que interpreta o ambiente que a circunscreve, ao mesmo tempo em que o constrói, por intermédio de suas ações.

Tomando-se, a priori, o comportamento organizacional como primeira categoria de análise, neste artigo, adota-se, também, o segundo pressuposto, no qual Argyris (1993) enuncia a suposição de que, se comportamentos novos são aprendidos, se os indivíduos os desejam implementar, e se esses indivíduos se permitem fazê-lo, então, pelo contexto, eles o farão.

Por meio dessa primeira categoria, amplia-se o conceito de comportamento dentro das organizações com Wagner III e Hollenbeck (2003, p. 6) que afirmam: 
comportamento organizacional é um campo de estudo voltado a prever, explicar, compreender e modificar o comportamento humano no contexto das empresas. Enfoca comportamentos observáveis. Estuda o comportamento das pessoas tanto como indivíduos quanto como membros de unidades sociais menores. Busca facilitar o entendimento de processos grupais e organizacionais.

Para fins deste artigo, os conceitos sobre comportamento foram utilizados para o entendimento dos processos organizacionais. Por se tratar de características organizacionais específicas, dentro de uma estrutura remota, isolada e confinada, a perspectiva do ser humano precisou ser olhada, não só como componente, mas também como alvo do processo.

Assim sendo, Casado (2007, p. 214), ao acolher tal perspectiva, concebe o comportamento organizacional:

como o conjunto de conhecimentos sobre o homem e sua interação com as demais pessoas, com seu trabalho e com outros aspectos da vida organizacional, que ajudam no entendimento das questões humanas e que concorrem para o atendimento dos objetivos organizacionais e para o desenvolvimento pleno do potencial humano.

Do mesmo modo, assumindo-se o comprometimento organizacional como segunda categoria de análise deste artigo, escolhe-se, como terceiro pressuposto teórico, o de Chang (2001), ao afirmar que a formação ou operacionalização do comprometimento do colaborador ocorre em ambiente dinâmico, que exige frequente atualização e enriquecimento da teoria e da prática relacionadas a esse construto.

Foram aqui utilizados dois sentidos (filosófico e psicológico) do comprometimento, com vistas a privilegiar a contribuição para o enfoque comportamental do construto comprometimento organizacional. A base escolhida para o sentido filosófico foi, fundamentalmente, buscada em Abbagnano (2003).

Dessa forma, recorrendo-se à filosofia existencialista, depreende-se que o comprometimento pode assumir sentido de compromisso, decisão ou escolha. A idéia do envolvimento que antecede ao ato de decidir ou escolher foi trazida por Heidegger. Sartre viu, no engajamento, o nascimento do projeto fundamental que é a expressão da liberdade humana e disse que o ser humano é a solução do problema e faz existir essa solução com o engajamento, somente com o qual é capaz de atingir a solução e vivê-la.

Os estudos de Robbins (2002, 2005) abarcam a participação, o envolvimento e o comprometimento como três atitudes crescentes. Com isso, o autor considera que um indivíduo só pode envolver-se em seu trabalho quando participa ativamente dele, identifica-se psicologicamente com ele e considera o seu desempenho como algo valioso para si. De igual forma, o indivíduo só está apto a comprometer-se quando se identifica com uma organização e com os seus objetivos, desejando manter-se parte dessa organização.

O pensamento de filósofos como Heidegger e Sartre, também visto em Robins, é reforçado pela psicologia, na qual se pode apreender que o indivíduo que se considera a si mesmo e à sua situação, claramente e livremente assume a responsabilidade por seu próprio ser e por tal situação, revela-se, com nitidez, em importantes aspectos do seu comportamento.

Sob essas condições, o comprometimento com os propósitos e o significado da vida é um dos mais importantes elementos de mudança de comportamento, como enfatiza Rogers (1977). 
Em sentido psicológico, Rogers entende que é fácil dar ao comprometimento significação demasiadamente superficial, indicando que a pessoa, por uma simples escolha consciente, se comprometeu num ou noutro curso de ação. Ele atribui significado bem mais profundo e afirma que o comprometimento pessoal é uma direção organísmica total, envolvendo não só o espírito consciente, mas, por igual, a direção de todo o organismo. É o tipo de comprometimento, no sentido do qual o autor crê que os indivíduos possam se encaminhar.

Essa segunda categoria de análise é respaldada pelos autores Bastos et al. (2008), quando salientam que as diferenças encontradas entre as definições de comprometimento organizacional estão relacionadas aos detalhes relativos à natureza ou à origem de forças que direcionam o comportamento. Eles relembram a necessidade de tratar o comprometimento a partir dos indicadores comportamentais ou de processos que vinculem o indivíduo a um curso específico de ação.

Ressalte-se que o modo como essa vinculção é formada, tanto para o indivíduo quanto para a organização, depende do tipo de contrato psicológico estabelecido entre ambos, conforme enfatizado por Handy (1978), que o classifica como contrato calculista e contrato cooperativo.

Para o estabelecimento de tal contrato, formador dessa vinculação, na visão de Dessler (1996), poucos atinariam para o fato de que a forma mais poderosa de garantir a execução correta do trabalho de uma organização é sincronizar as suas metas com as de seus funcionários.

Isso equivale garantir, em outras palavras, que os dois conjuntos de metas sejam essencialmente os mesmos, de modo que, ao procurar realizar suas próprias metas, o funcionário procure realizar também as metas da organização. Criar comprometimento significa forjar tal síntese, que, por sua vez, implica facilitar a gestão das pessoas na organização. A gestão estratégica de pessoas é também, a priori, a terceira categoria de análise deste artigo.

Portanto, cabe inserir, aqui, o quarto pressuposto teórico, no qual Albuquerque (2002) enfatiza que, para a formulação da estratégia de gestão de pessoas interessa aprofundar os aspectos relativos às dimensões humanas, ou seja, a cultura e as pessoas e como a interação das pessoas com a estrutura e com o sistema pode contribuir para a consecução dos objetivos estratégicos da organização. E, em linha com o que foi tratado até então, Casado (2007, p. 213) afirma que "os fundamentos conceituais das ações de gestão de pessoas têm suas raízes no estudo sobre comportamento humano nas organizações". A autora enfatiza a necessidade de se despender tempo e energia no estudo e na compreensão de comportamento organizacional para obter melhor entendimento na aplicação das ferramentas de gestão de pessoas. Relembrese que o comportamento organizacional é a primeira categoria de análise adotada para este artigo.

Registre-se que, para o enfoque estratégico da gestão de pessoas, o conceito de administração estratégica de recursos humanos já é observado em evolução, resultante da crescente necessidade de orientação para planejamento e de intervenções gradativas com orientações estratégicas, visando à mudança do modelo de controle para o de comprometimento (Davel e VERGARA, 2001; ALBUQUERQUE 1999). Esses autores sugerem que diversos subsistemas - a estrutura organizacional, as relações de trabalho e as políticas de $\mathrm{RH}$ - compõem a gestão de pessoas e são compostos de políticas e práticas, podendo ser combinados de forma a produzir diferentes estratégias.

Saliente-se que os desafios da evolução do conceito de gestão de pessoas, por meio da mudança da estratégia de controle para a estratégia do comprometimento, sugerem, em última instância, uma deliberação de mudança, em nível comportamental nas organizações, de acordo com Albuquerque (1999). Na estratégia de controle, Walton (1997) deixa claro que, há 
pouca definição de políticas em relação à voz do funcionário. O pressuposto desse modelo é de baixo comprometimento do funcionário. O autor diz que, na estratégia de comprometimento, esperam-se mudanças nas responsabilidades individuais, à medida que as condições mudem e as equipes, não os indivíduos, sejam as unidades organizacionais responsáveis pelo desempenho.

Como forma de tornar o processo estratégico mais interativo e contínuo, estimulando a comunicação, o aprendizado e o comprometimento das pessoas, a participação mais ampla de colaboradores de diferentes níveis da organização é exigida na formulação da estratégia.

No que tange à participação dos profissionais de RH na formulação dessa estratégia, diversos autores entendem ser esse o novo papel do RH (ALBUQUERQUE, 2002; ANTHONY, PERREWÉ e KACMAR, 1996; ULRICH, 1998; BECKER, HUSELID e ULRICH, 2001).

Os cuidados para compreender as diversas definições acerca da natureza da gestão de pessoas, incluindo as várias maneiras como ela acontece em diferentes contextos organizacionais, são reforçados por Mascarenhas (2008). Imagina-se que, com relação à estrutura organizacional, sob as circunstâncias de distanciamento dos grandes centros, isolamento e confinamento, tais cuidados precisem ser mais enfatizados.

Elegendo-se como quarta categoria de análise, deste artigo, a cultura organizacional, tome-se como quinto pressuposto teórico o que advogam Fleury e Fleury (1997): uma forte cultura pressupõe o comprometimento dos empregados com os objetivos organizacionais.

Esse pressuposto está em linha com Schein (1987), que trata a responsabilidade por sedimentar e reforçar a cultura de modo associado também ao tipo de estrutura organizacional. Se a estrutura é centralizada, reflete a crença de que somente o líder pode determinar o que é melhor; se é descentralizada, reflete uma crença na iniciativa individual e na responsabilidade compartilhada.

Na mesma linha de pensamento, Stacey (1991) afirma que o equilíbrio do sistema de poder e cultura é identificado em quatro estados, a saber: (1) onde há uma clara hierarquia e grande concentração de poder sem compartilhamento dos valores e da cultura, leva à força com submissão, baixo consentimento e rebelião dos integrantes; (2) em uma estrutura complexa, na qual o poder é disperso e fracamente exercido, com forte compartilhamento de valores e alto grau de consentimento, leva ao vácuo do poder; (3) onde existe uma clara hierarquia e concentração/exercício do poder, com forte compartilhamento dos valores e da cultura, leva a uma forte integração organizacional, caracterizando autoridade e obediência; e (4) onde há a dispersão do poder e fraca intenção de usá-lo, com baixa integração cultural, leva à rivalidade.

Com esse breve diálogo entre os autores dos pressupostos teóricos dessa fundamentação, espera-se que seja possível forjar a síntese que conduza ao diálogo teórico-empírico na discussão dos resultados deste artigo, passando antes pelos aspectos metodológicos e apresentação dos resultados encontrados nas especificidades da empresa aqui utilizada como unidade de análise.

\section{Aspectos metodológicos}

Na primeira parte desta pesquisa, realizou-se um breve levantamento bibliográfico, do qual foram retirados os pressupostos teóricos que se alinhavam às categorias de análise (comportamento organizacional, comprometimento organizacional, gestão estratégica de pessoas e cultura organizacional), consideradas por Vergara (2005) como parte da grade fechada, por serem definidas preliminarmente. Tais categorias são pertinentes ao objetivo da pesquisa, e os elementos identificados no material selecionado lhes são integrados no decorrer da pesquisa. 
A partir da escolha desses pressupostos, pertinentes ao objetivo e ao problema de pesquisa, foram construídos os roteiros de entrevistas e observações, determinando a natureza qualitativa da investigação. Neste artigo, a escolha prioritária do método qualitativo recaiu na possibilidade de permitir analisar aspectos subjetivos, tais como: compreensão do contexto da organização, percepções, compartilhamento dos significados e dinâmica das interações grupais, por intermédio de seus significados para as pessoas, de acordo com Richardson (1989).

A pesquisa qualitativa foi desenvolvida a partir do cruzamento de diversas disciplinas, campos e objetos. De acordo com Denzin e Lincoln (1998, p. 3), ela é "focada em multimétodos, envolvendo uma perspectiva interpretativa e naturalista de seus problemas. Isso significa que os pesquisadores qualitativos estudam os problemas em seus espaços, tentando fazer sentido ou interpretar os fenômenos em termos de significados que as pessoas lhes trazem".

Acresça-se a isso, o enunciado por Denzin e Lincoln $(1998,2000)$, de que a pesquisa qualitativa envolve a coleta de uma variedade de materiais empíricos, dentre eles a estratégia de estudo de caso. Tal estratégia foi escolhida, neste artigo, pelas seguintes razões: os estudos de caso colocam mais ênfase em uma análise contextual completa de poucos fatos ou condições e suas inter-relações, conforme elucidado por Cooper e Schindler (2003); tal estratégia, com base em Eisenhardt (1989), pode ser realizada, dependendo da técnica utilizada na coleta, análise e interpretação dos dados; é apropriada, de acordo com Yin (2005), por não exigir controle sobre eventos comportamentais; focalizar acontecimentos contemporâneos; acrescentar fontes de evidências, como entrevistas de pessoas envolvidas nos acontecimentos que estão sendo estudados; realizar observação desses acontecimentos, documentos e artefatos; possibilitar a investigação de um fenômeno e seus conteúdos da vida real quando as fronteiras entre o fenômeno e o contexto ainda não estão claramente evidentes.

Em sua segunda fase, esta pesquisa contou com um levantamento de campo, com vistas à obtenção de respostas à questão: como as especificidades na gestão de pessoas são elucidadas dentro da empresa Mineração Rio do Norte - MRN?

Esse levantamento de campo envolveu um grupo constituído de diretores, gerentes, profissionais de $\mathrm{RH}$, supervisores e coordenadores da MRN, perfazendo um total de dezenove pessoas. Os dados primários foram coletados por meio de entrevistas em profundidade e observações sistemáticas, nas áreas operacionais e assistemáticas nos locais das entrevistas; os secundários, por meio de análise de documentos fornecidos pela empresa.

Ressalte-se que a estrutura organizacional remota foi considerada como critério de escolha do universo desta pesquisa. A Mineração Rio do Norte, aqui tomada como unidade de análise, opera com estrutura organizacional considerada remota, isolada e confinada. Ela é uma associação de empresas nacionais e internacionais, instalada no núcleo urbano de Porto Trombetas, município de Oriximiná, situado no Oeste do Pará, região Norte do Brasil.

Trata-se, portanto, neste artigo, de um estudo de caso único, cujo nível proposto de análise é o organizacional. A MRN tem como missão "produzir bauxita e fornecer o minério com pleno atendimento às especificações de qualidade, assegurando a satisfação dos clientes e o retorno adequado do investimento de acionistas, mantendo uma relação de profundo respeito ao homem e à natureza".

Suas operações começaram, em 1979, e consistem na extração, beneficiamento, transporte ferroviário, secagem e embarque em navios de minério de bauxita, a matéria-prima do alumínio. A exploração da bauxita é feita em mina a céu aberto. A maior parte da sua produção é destinada ao mercado interno. A Mineração Rio do Norte tem, como vias de acesso, o rio Trombetas ou o aeroporto próprio. A concepção dessa empresa envolveu a criação de toda a infraestrutura necessária à sua operação. 
Para tratamento dos dados coletados, foram utilizadas as técnicas de análises de conteúdo das entrevistas e documental, bem como a metodologia reflexiva. A análise de conteúdo é considerada uma técnica para o tratamento de dados, que visa a identificar o que está sendo dito a respeito de determinado tema.

Foi ressaltado, por Marconi e Lakatos (1982), que a análise de conteúdo, além de voltar-se para o estudo das ideias, ao invés das palavras, é uma técnica que tem como alvo os produtores da ação humana, o que justifiva a sua utilização, neste artigo.

Segundo Bardin (1977, p. 42), a análise de conteúdo é: “um conjunto de técnicas de análise das comunicações visando obter, por procedimentos sistemáticos e objetivos de descrição do conteúdo das mensagens, indicadores (quantitativos ou não) que permitam a inferência de conhecimentos relativos às condições de produção / recepção destas mensagens". Para essa autora, a análise de conteúdo não deve ser nem doutrinária, nem normativa.

A metodologia reflexiva caracteriza-se pelo fato de que todas as referências para dados empíricos são resultados de interpretação e reflexão, de acordo com Vergara (2005). A autora enfatiza que, na metodologia reflexiva, fundamentação teórica e coleta de dados empíricos caminham conjuntamente.

\section{Apresentação e análise dos resultados}

O Quadro 01 mostra o resultado da análise de conteúdo das dezenove entrevistas realizadas na Mineração Rio do Norte, no qual as unidades de codificação, representadas por palavras-tema e respaldadas por palavras-chave ou frases-chave, foram tomadas de segmentos do conteúdo das entrevistas constituídos de significação para os objetivos da pesquisa.

O agrupamento foi feito observando-se a sequência na qual pudessem ser contemplados os termos: comportamento organizacional, comprometimento organizacional, gestão de pessoas e cultura organizacional, representantes das quatro categorias de análise deste estudo.

Do mesmo modo, foi realizado o reagrupamento das palavras-chave ou fraseschave que representassem melhor as vinte e oito palavras-tema, denominadas unidades de codificação, embutidas nessas quatro categorias.

Para mostrar a presença ou ausência dessas palavras ou frases, escolheu-se, auxiliarmente, fazer a contagem do número de vezes em que elas estiveram presentes ou ausentes, sem contar a ocorrência das repetições dessas palavras ou frases no conteúdo de uma mesma entrevista. 


\begin{tabular}{|c|c|c|c|}
\hline \multirow{2}{*}{$\begin{array}{l}\text { Unidade de codificação } \\
\text { palavras-tema }\end{array}$} & \multirow[t]{2}{*}{ Palavras-chave ou frases-chave } & \multicolumn{2}{|c|}{ Contagem } \\
\hline & & Presença & Ausência \\
\hline 1. Feedback & $\begin{array}{l}\text { Estímulo; } \\
\text { Evidência. }\end{array}$ & $\begin{array}{l}16 \\
19\end{array}$ & $\begin{array}{l}03 \\
-\end{array}$ \\
\hline 2. Interações & Integrantes dos diversos escalões. & 17 & 02 \\
\hline 3. Abertura & $\begin{array}{l}\text { Encorajamento para debates; } \\
\text { Ocorrência de debates. }\end{array}$ & $\begin{array}{l}19 \\
19 \\
\end{array}$ & $\begin{array}{l}- \\
-\end{array}$ \\
\hline 4. Comunicações interpessoais & Ocorrência entre as áreas. & 15 & 04 \\
\hline 5. Emoções & Expressão. & 17 & 02 \\
\hline 6. Pensar, sentir e agir & Evidência de interface. & 16 & 03 \\
\hline 7. Tomada de decisão & Ocorrência em grupo. & 19 & - \\
\hline 8. Comportamento intergrupal & Favorecendo o trabalho em equipe. & 18 & 01 \\
\hline 9. Participação & Estímulo à atitude de participação do empregado. & 19 & - \\
\hline 10. Envolvimento & $\begin{array}{l}\text { Estímulo à atitude de envolvimento do empregado com os objetivos } \\
\text { organizacionais. }\end{array}$ & 19 & - \\
\hline 11. Comprometimento & $\begin{array}{l}\text { Estímulo à atitude de comprometimento (identificação) do } \\
\text { empregado com os objetivos organizacionais. }\end{array}$ & 18 & 01 \\
\hline 12. Expectativas & $\begin{array}{l}\text { Possibilidade de o empregado comunicar expectativas em relação à } \\
\text { empresa; } \\
\text { Ocorrência de comunicação das expectativas da empresa em relação } \\
\text { ao empregado. }\end{array}$ & 18 & $\begin{array}{l}01 \\
08\end{array}$ \\
\hline 13. Responsabilidades & $\begin{array}{l}\text { Estímulo para o empregado assumir responsabilidades sobre suas } \\
\text { ações. }\end{array}$ & 19 & - \\
\hline 14. Engajamento & $\begin{array}{l}\text { Estímulo ao engajamento das pessoas aos objetivos e metas } \\
\text { organizacionais. }\end{array}$ & 19 & - \\
\hline 15. Características da unidade & $\begin{array}{l}\begin{array}{l}\text { Estimulando as pessoas a despenderem esforços para nela } \\
\text { permanecerem. }\end{array} \\
\end{array}$ & 17 & 02 \\
\hline 16. Cooperação & $\begin{array}{l}\text { Estímulo à atitude de cooperação; } \\
\text { Evidência da cooperação. }\end{array}$ & $\begin{array}{l}18 \\
19 \\
\end{array}$ & $\begin{array}{l}01 \\
- \\
\end{array}$ \\
\hline 17. Valorização & $\begin{array}{l}\text { Evidência da valorização de opiniões e descobertas em relação à } \\
\text { maneira de se obter resultados; } \\
\text { Evidência da valorização do trabalho. }\end{array}$ & $\begin{array}{l}16 \\
19 \\
\end{array}$ & 03 \\
\hline $\begin{array}{l}\text { 18. Aprendizagem / Reapren- } \\
\text { dizagem }\end{array}$ & $\begin{array}{l}\text { Reconhecimento da necessidade de aprendizagem / reaprendizagem } \\
\text { em relação ao trabalho. }\end{array}$ & 16 & 03 \\
\hline 19. Desenvolvimento & $\begin{array}{l}\begin{array}{l}\text { Demonstração do estímulo ao desenvolvimento } \\
\text { profissional na própria organização. }\end{array} \\
\end{array}$ & 18 & 01 \\
\hline 20. Incentivos & $\begin{array}{l}\text { Disponibilização de incentivos vinculados a resultados obtidos pela } \\
\text { equipe. }\end{array}$ & 15 & 04 \\
\hline 21. Reconhecimento & $\begin{array}{l}\text { As pessoas são capazes de: desenvolvimento, confiança e } \\
\text { colaboração. }\end{array}$ & 19 & - \\
\hline $\begin{array}{l}\text { 22. Características organiza- } \\
\text { cionais da empresa }\end{array}$ & $\begin{array}{l}\text { Atrair e reter pessoas de alto potencial e qualificação para o } \\
\text { trabalho. }\end{array}$ & 12 & 07 \\
\hline \multirow{2}{*}{$\begin{array}{l}\text { Unidade de Codificação } \\
\text { Palavras-tema }\end{array}$} & \multirow[t]{2}{*}{ Palavras-chave ou Frases-chave } & \multicolumn{2}{|c|}{ Contagem } \\
\hline & & Presença & Ausência \\
\hline $\begin{array}{l}\text { 23. Criação de condições de } \\
\text { trabalho na empresa }\end{array}$ & $\begin{array}{l}\text { Favoráveis à manutenção da motivação individual para o trabalho; } \\
\text { Favoráveis à mobilização dos grupos em torno das metas } \\
\text { organizacionais. }\end{array}$ & $\begin{array}{l}16 \\
19\end{array}$ & $\begin{array}{l}03 \\
-\end{array}$ \\
\hline $\begin{array}{l}\text { 24. Estrutura organizacional da } \\
\text { unidade }\end{array}$ & $\begin{array}{l}\text { Valorizando somente o que a liderança determina; } \\
\text { Valorizando a iniciativa individual; } \\
\text { Valorizando o poder concentrado na liderança; } \\
\text { Valorizando a responsabilidade compartilhada. }\end{array}$ & $\begin{array}{l}02 \\
13 \\
04 \\
18 \\
\end{array}$ & $\begin{array}{l}17 \\
06 \\
15 \\
01 \\
\end{array}$ \\
\hline 25. Comunicação & $\begin{array}{l}\text { Acerca do que é esperado do desempenho das pessoas; } \\
\text { Dos acontecimentos críticos que marcam a história da unidade; } \\
\text { Ocupação da unidade em saber como está sendo percebido o seu } \\
\text { processo de comunicação formal e informal. }\end{array}$ & $\begin{array}{l}13 \\
17 \\
19\end{array}$ & $\begin{array}{l}06 \\
02 \\
-\end{array}$ \\
\hline 26. Missão organizacional & $\begin{array}{l}\text { Ocupação da unidade em saber como está sendo compreendida sua } \\
\text { missão. }\end{array}$ & 17 & 02 \\
\hline
\end{tabular}

Fonte: os autores, com base nos dados da pesquisa.

Quadro 1 - Base da análise de conteúdo. 
As unidades de codificação 1 a 8 dizem respeito às palavras-tema contidas na categoria comportamento organizacional. A contagem de presenças totalitárias nas unidades de codificação 1 (palavra-chave 2), 3 (ambas as frases-chave) e 7, assim como presenças expressivas nas unidades 2, 4, 5, 6 e 8, mostra uma visão favorável dos entrevistados em relação à categoria comportamento organizacional. Contudo, as ausências contidas nas palavras-tema 1, 4 (com mais ênfase) e 6 não devem ser consideradas desprezíveis e podem ser conduzidas a um diálogo investigativo das razões.

As unidades de codificação 9 a 16 estão voltadas para as palavras-tema contidas na categoria comprometimento organizacional. A contagem de presenças é quase totalitária em todas elas e denota a favorabilidade, na percepção dos entrevistados, com relação a essa categoria. Porém, a unidade de codificação 12, em sua frase-chave 2, mostra que as ausências são bastante significativas e necessitam de investigação das razões que estão nelas embutidas.

As unidades de codificação 17 a 23 referem-se às palavras-tema contidas na categoria gestão estratégica de pessoas. As presenças são totalizadoras nas unidades de codificação 17 (frase-chave 2), 21 e 23 (frase-chave 2); quase totalizadoras na unidade de codificação 19; são significativas nas unidades de codificação 17 (frase-chave 1), 18 e 23 (frase-chave 1) e todas elas denotam a visão positiva que os entrevistados têm dessa categoria nessa empresa. Entretanto, as ausências observadas na unidade de codificação 22 são significativas e mostram necessidade de investigação para a compreensão das razões.

As unidades de codificação 24 a 28 estão no bojo das palavras-tema contidas na categoria cultura organizacional. Observam-se, no Quadro 1, as ausências substanciais na unidade de codificação 24 - estrutura organizacional da unidade - representada pelas fraseschave "valorizando somente o que a liderança determina" e "valorizando o poder concentrado na liderança".

As frases-chave "valorizando a responsabilidade compartilhada" e "valorizando a iniciativa individual", com as presenças registradas, mostram-se com resultados representativos para a confirmação da ausência de rigidez, autoritarismo e centralização nas determinações da liderança, ressaltadas nas outras duas frases-chave.

A unidade de codificação 25 (frase-chave 1) mostra ausências não desprezíveis. As unidades de codificação 25 (frases-chave 2 e 3), 26, 27 e 28 apresentam confirmação da visão favorável dos entrevistados nos aspectos concernentes à categoria cultura organizacional dessa empresa.

Os resultados da análise de conteúdo aplicadada ao escopo da pesquisa são apresentados no Quadro 2 e contribuem para aprofundar a compreensão do que foi mostrado no Quadro 1, principalmente pelo extrato das especificidades da empresa em cada uma dessas quatro categorias. 


\begin{tabular}{|c|c|c|}
\hline Categorias de análise & Temas aignificativos & Unidade de codificação \\
\hline $\begin{array}{c}\text { Comportamento } \\
\text { Organizacional }\end{array}$ & $\begin{array}{l}\text { Percepção da con- } \\
\text { tribuição dos indi- } \\
\text { víduos, dos grupos e } \\
\text { da estrutura. }\end{array}$ & $\begin{array}{l}\text { "A estrutura remota facilita, porque aproxima as pessoas inclusive aos finais } \\
\text { de semana. A solidariedade é grande." } \\
\text { "Os grupos de CCQ contribuem muito e são elogiadíssimos." } \\
\text { "A MRN é um grande laboratório: universidade particular com abertura e } \\
\text { facilitação. Patrocina a evolução das pessoas pela disponibilização de } \\
\text { recursos." } \\
\text { "A integração entre o discurso e a prática está bem afinada." } \\
\text { "Contribuição contínua, liberdade para aprender e mudar são tônicas da } \\
\text { estrutura criada e mantida nessa empresa." }\end{array}$ \\
\hline $\begin{array}{c}\text { Comprometimento } \\
\text { Organizacional }\end{array}$ & $\begin{array}{l}\text { Percepção do orgulho } \\
\text { e do empenho } \\
\text { exercido pelos in- } \\
\text { divíduos em favor } \\
\text { dessa empresa. }\end{array}$ & $\begin{array}{l}\text { "As pessoas têm orgulho e expressam isso na pesquisa de clima. Todos são } \\
\text { comprometidos e têm empenho com os resultados." } \\
\text { "Com brilho nos olhos, as pessoas demonstram o seu orgulho em todas as } \\
\text { ocasiões." } \\
\text { "Os olhos brilham quando se fala da empresa. Os gerentes começaram como } \\
\text { operadores. Isso gera orgulho. As pessoas de fora podem vir, mas as de dentro } \\
\text { são priorizadas." } \\
\text { "O fato de muita gente ser da região aumenta o orgulho." } \\
\text { "As pessoas demonstram o orgulho pelo que fazem em todas as } \\
\text { circunstâncias." } \\
\text { "O orgulho é muito forte. O empenho ocorre frequentemente com a grande } \\
\text { maioria das pessoas." } \\
\text { "Orgulho e empenho caminham juntos. Algo a mais é feito sempre, como se } \\
\text { fosse autodesafio." }\end{array}$ \\
\hline $\begin{array}{c}\text { Gestão Estratégica } \\
\text { de Pessoas }\end{array}$ & $\begin{array}{l}\text { Percepção da adoção } \\
\text { de novas práticas de } \\
\text { gestão, de modo a } \\
\text { facilitar as ações de } \\
\text { desenvolvimento e } \\
\text { resolução de conflitos } \\
\text { nessa empresa. }\end{array}$ & $\begin{array}{l}\text { "O envolvimento de todos, do topo ao chão da fábrica, mostram o que tem } \\
\text { por trás da política de gestão participativa de pessoas." } \\
\text { "As principais práticas de gestão são a de segurança e de relacionamento } \\
\text { interpessoal." } \\
\text { "Os planos de ação para melhoria do clima organizacional e ouvidoria } \\
\text { proporcionam resolução para tipos específicos de conflitos." } \\
\text { "Há um quadro maduro. O tempo de empresa das pessoas aqui é alto." }\end{array}$ \\
\hline $\begin{array}{c}\text { Cultura } \\
\text { Organizacional }\end{array}$ & $\begin{array}{l}\text { Percepção do conhe- } \\
\text { cimento que os } \\
\text { indivíduos têm, acerca } \\
\text { da visão, filosofia de } \\
\text { atuação, missão e } \\
\text { valores nessa empre- } \\
\text { sa. }\end{array}$ & $\begin{array}{l}\text { "Todos entendem os valores, principalmente segurança, responsabilidade } \\
\text { social, cooperação, solidariedade, meio-ambiente e parceria estão } \\
\text { impregnados nas pessoas." } \\
\text { "O amadurecimento e a consciência para políticas, valores e princípios são } \\
\text { muito fortes." } \\
\text { "Não é permitido produzir sem segurança aqui. A segurança está injetada nas } \\
\text { ações das pessoas, principalmente das que estão expostas aos riscos." } \\
\text { "A cultura é muito forte para a preservação da vida, segurança, saúde e meio- } \\
\text { ambiente. As comunidades ribeirinhas já incorporaram essa cultura." } \\
\text { "Pode até terminar em demissão, se a pessoa for irresponsável consigo } \\
\text { mesma." }\end{array}$ \\
\hline
\end{tabular}

Fonte: os autores, com base nos dados da pesquisa.

Quadro 2 - Base da análise de conteúdo aplicada ao escopo da pesquisa. 
Pela análise dos resultados na categoria comportamento organizacional, tem-se que a estrutura da MRN é considerada de excelência para promover a contribuição das pessoas em prol dos resultados organizacionais. O seu foco volta-se para a melhoria contínua do processo de gestão e clima organizacional. Visitas a outras empresas, com unidades remotas, são práticas sistematizadas para o desenvolvimento das pessoas. Há o reconhecimento das melhorias a serem empreendidas e os processos estão em constante mutação.

Segundo os dados das entrevistas, a confiança é imprescindível para a operação e há um aprendizado constante de contribuição, pelo trabalho em equipe. As pessoas sabem o que fazer, como fazer, e o porquê fazer. Não há necessidade de supervisão acirrada. Esse é um dos fatores que compõem as políticas dessa empresa. Os entrevistados consideram, ainda, que o trabalho é prioritariamente desenvolvido em conjunto e o amadurecimento das pessoas, com muitos anos nessa estrutura, é relevante para os resultados.

$\mathrm{Na}$ categoria comprometimento oraganizacional, o orgulho de pertencer à empresa é demonstrado de formas variadas: os mais antigos, o fazem com o tempo empenhado em prol dos melhores resultados; os que chegam, com a garra para fazerem parte da estrutura, elevadamente empenhados em conquistar oportunidades; indicar oportunidades para familiares, amigos ou parentes mais distantes é outra forma de demonstração. Conforme os documentos analisados, a dimensão identidade organizacional é a mais pontuada nas pesquisas de clima e satisfação.

O envolvimento de todos os escalóes com os objetivos da empresa, bem como a preparação de pessoas para ocuparem cargos mais avançados, contribui para o processo de obtenção do comprometimento organizacional. As pessoas que não conseguem adaptar-se ao conjunto de variáveis dessa estrutura remota, isolada e confinada terminam passando pouco tempo. Não há meio-termo. As que chegam demonstram orgulho em contribuir com a sua história. As que saem para outras unidades organizacionais orgulham-se de terem sido escolhidos pelas competências adquiridas na Mineração Rio do Norte e no núcleo de Trombetas.

Com a categoria de gestão estratégica de pessoas depreende-se que todas as açõesdiárias reforçam a política da empresa. Os diálogos de segurança elucidam valores como segurança, meio-ambiente, saúde, relacionamento com a comunidade. Os princípios norteadores da empresa são divulgados com frequentes reciclagens e, a condição de confinamento propicia a percepção das ações assimiladas pelos moradores.

Os resultados desta pesquisa denotam a existência de políticas e práticas específicas de gestão de pessoas, a exemplo de: política de gestão participativa de pessoas, do topo ao chão da fábrica; práticas de gestão de segurança e de relacionamento interpessoal dentro e fora dos muros da empresa; planos de ação para melhoria do clima organizacional e ouvidoria para resolução de tipos específicos de conflitos; contribuições efetivadas pelos grupos de CCQ; alinhamento entre o discurso e a prática incentivado em todos os níveis; política de abertura e facilitação em todos os níveis; disponibilização de recursos para evolução das pessoas; liberdade para aprender e mudar, em todos os níveis.

Uma especificidade dessa empresa é que os gerentes começaram nela como operadores. O presidente reside na comunidade e convive com todos os integrantes da equipe organizacional. Oriundo de uma área de operação da própria empresa, o presidente enfatiza como práticas decorrentes das políticas específicas, os programas: café com o presidente e com a direção da empresa que permite troca e funciona como mais uma ação de gestão; programas com jovens aprendizes e de educação de jovens e adultos; gestão por competências; resoluções de conflitos nos relacionamentos com empregados; conselho de comunicação; crescer em 
equipe; convênios com instituições de capacitação; reeducação para a resolução de conflito face-a-face; projetos de integração com as famílias e de guia para morar em Trombetas.

O programa de visita às áreas, envolvendo os familiares, é outra especificidade dessa empresa, já premiado pela Associação Brasileira de Comunicação Empresarial duas vezes, a primeira no Regional e a segunda no Nacional. Para os entrevistados, isso tudo gera orgulho, pois, fica claro que, as pessoas de fora podem chegar a fazer parte do corpo gerencial, mas, as de dentro são priorizadas para crescerem e desenvolverem suas habilidades e competências.

Os dados documentais, de entrevistas e observações mostram que a liberdade para desenvolver políticas e filosofia próprias, envolvendo erros e acertos, é parte integrante da história dessa empresa. Existe treinamento para os aposentáveis aprenderem a viver fora da empresa e da comunidade. Os entrevistados afirmam que não há descaracterização da Mineração Rio do Norte, como ela é, por parte dos acionistas e exemplo da Vale, detentora de $40 \%$ das ações. Esses entrevistados reafirmam que os acionistas trazem novas contibuições e reconhecem as contribuições oriundas da MRN.

$\mathrm{Na}$ categoria de cultura organizacional, de acordo com os entrevistados, as pessoas conhecem bem a visão, os valores, a missão e a filosofia de atuação nessa empresa. Existe um programa de revisão que ajuda a memorizar e, a cada seis meses, um programa de validação. Algumas auditorias checam e consideram que as pessoas sempre respondem bem aos questionamentos nessa categoria.

Tanto a análise documental quanto as entrevistas demonstraram que valores como segurança, responsabilidade social, cooperação, solidariedade, parceria, qualidade de vida, abertura para o diálogo, respeito às individualidades, saúde, e meio-ambiente fazem parte da cultura dentro da MRN e no núcleo urbano de Porto Trombetas.

Do mesmo modo, os dados da pesquisa reiteram que a cultura de preservação é fortemente percebida na localidade, por meio da participação no programa de consciência ecológica, o qual contribui para as comunidades ribeirinhas incorporarem essa cultura, cuidando da saúde, segurança e meio-ambiente.

\section{Discussão dos resultados}

Retomem-se, nesse tópico, os pressupostos teóricos adotados na breve fundamentação teórica desta pesquisa, acrescidos do respaldo empírico obtido por meio das entrevistas, das observações e dos documentos, para enriquecer a discussão dos resultados obtidos.

Por meio do primeiro pressuposto, baseado em Pereira (2004) e reforçado por Vasconcelos (2004), pode-se dizer que, à empresa estudada, pelo próprio contexto em que está inserida, pelo caráter isolado e confinado, cabe a tarefa de interpretar o ambiente e construí-lo.

Tal tarefa pode ser desenvolvida, quer escolhendo a melhor forma para o agrupamento de recursos humanos e materiais (departamentalização) quer consolidando a definição de autoridade, atividades e comunicação (atribuições), necessárias para cumprir a sua missão organizacional ou, ainda, cuidando de gerenciar a infraestrutura (departamentalização e atribuições) que denomina a estrutura organizacional remota. E, em decorrência, desempenhando sua função social e contribuindo para que as pessoas tenham um modo de vida.

O caso da MRN deixa claro quão imperativa se torna a necessidade de desenvolver a capacidade de aprendizagem de comportamentos novos, bem como o desejo e a permissão interna e externa, aos indivíduos, de implementá-los no contexto em que estão inseridos. Tal 
fato está associado ao segundo pressuposto, tomado de Argyris (1993) e, à primeira categoria de análise, estabelecida para este artigo.

No terceiro pressuposto teórico, oriundo dos estudos de Chang (2001) e alinhado à segunda categoria de análise, é percebido o movimento da busca constante pela criação de condições favoráveis ao engajamento, à participação, ao envolvimento e ao comprometimento das pessoas com os objetivos organizacionais, observando-se os cuidados por parte dos gestores com o ambiente no qual a empresa está inserida.

Com o quarto pressuposto, baseado em Albuquerque (2002), associado à terceira categoria de análise, tem-se a observação do esforço engendrado pela organização estudada, no sentido de contemplar os aspectos relativos às dimensões humanas, tanto nas atividades de trabalho quanto no núcleo urbano de Porto Trombetas.

Verifique-se, com a quarta categoria de análise, o quinto pressuposto teórico, qual seja o de que uma forte cultura pressupõe o comprometimento dos empregados com os objetivos organizacionais, de acordo com Fleury e Fleury (1997). Pelo próprio contexto no qual a empresa está inserida o registro se fez notório e há a percepção de uma cultura própria, adaptada à realidade de Trombetas.

Registre-se que, de acordo com a classificação dada por Handy (1978), o predomínio do tipo de contrato psicológico cooperativo é o que melhor se encaixa na necessidade de dar fundamento às bases de vínculos encontradas nessa empresa remota, isolada e confinada.

É salientado por Stacey (1991) que onde existe uma clara hierarquia e concentração / exercício do poder com forte compartilhamento dos valores e da cultura, leva a uma forte integração organizacional, caracterizando autoridade e obediência.

Os resultados da pesquisa mostram que o poder é exercido de modo a facilitar a integração organizacional e o reconhecimento natural da hierarquia, conforme destacado na unidade de codificação no. 24, do quadro no 01, "Base da Análise de Conteúdo".

A deliberação de mudança em nível comportamental nessa organização é considerada como condição indubitável para assegurar a operacionalização das atividades, segundo os dados desta pesquisa. Saliente-se que, a responsabilidade compartilhada em grupos é destaque incentivado.

Por fim, registre-se que, em função do aquecimento do mercado de minerais, os entrevistados consideram que atrair e reter talentos têm sido os desafios da empresa. Estrategicamente, práticas salariais e de benefícios não podem ser equiparadas com localidades próximas aos grandes centros, pois, o risco de não conseguir alcançar esse processo de retenção se torna muito mais elevado.

\section{Considerações finais}

Relembre-se que este artigo teve como principal objetivo investigar como as especificidades na gestão de pessoas são elucidadas dentro da Mineração Rio do Norte, uma empresa com estrutura organizacional remota, isolada e confinada.

A questão de pesquisa acerca dessas especificidades foi respondida em todas as quatro categorias de análise, nas quais foram destacados pontos que denotam visão favorável dos entrevistados, tanto nos registros de presenças quanto no de auências. Registre-se, sobretudo, que as especificidades na gestão estratégica de pessoas, observadas dentro dessa empresa, são reforçadas para todos os níveis. 
Saliente-se, dentre esses pontos que, favoravelmente, chefias e colegas de todas as áreas e/ou da mesma área estimulam feedbacks, debates, engajamento, cooperação, valorização do trabalho, reconhecimento pela capacidade de desenvolvimento, confiabilidade e colaboração.

Evidencie-se que a natureza da estrutura remota, isolada e confinada, nessa organização, favorece, ainda, a busca da contribuição, da ajuda e do desenvolvimento da solidariedade. Nessa estrutura, os gestores exercem influência direta no processo de comprometimento organizacional, permitindo que os valores e a identidade organizacional sejam compartilhados por todos, dentro e fora do contexto de trabalho tornando o núcleo urbano de Porto Trombetas (cuidado por todos os integrantes da MRN), na opinião unânime dos entrevistados, um lugar aprazível para se viver, trabalhar e educar filhos.

Enfatize-se o predomínio do tipo de contrato psicológico cooperativo, apontado pelo resultado de pesquisa nessa empresa e, mostrado pela literatura, como o melhor para gerar compartilhamento, cooperação e colaboração. Nesse contrato, valores como saúde, segurança, responsabilidade social e meio-ambiente são considerados fundamentais.

Considere-se que os resultados encontrados nesta pesquisa não podem ser generalizados. Entretanto, certamente podem contribuir para a abertura de caminhos para novas investigações dentro de estruturas similares, distantes dos grandes centros urbanos, quer sejam: somente remotas; remotas e isoladas; remotas, isoladas e confinadas; somente semiremotas.

\section{Referências}

ABBAGNANO, N. Dicionário de filosofia. São Paulo: Martins Fontes, 2003.

ALBUQUERQUE, L.G. Estratégias de recursos humanos e competitividade. In: VIEIRA, M. M. F.; OLIVEIRA, L.M.B. (Orgs.). Administração contemporânea: perspectivas e estratégias. São Paulo: Atlas, 1999. p. 215-238.

ALBUQUERQUE, L.G. A gestão estratégica de pessoas. In: FLEURY, M. T. L. et al. (Coord.). As pessoas na organização. São Paulo: Gente, 2002. p. 35-50.

ANTHONY, W.P.; PERREWÉ, P.L.; KACMAR, M.K. Strategic human resource management. Florida: Harcourt Brace Publisher \& Co. 1996.

ARGYRIS, C. Knowledge for action. San

Francisco: Jossey-Bass, 1993.

BASTOS, A.V. B. et al. Comprometimento organizacional. In: SIQUEIRA, M.M.M. et al.

Medidas do comportamento organizacional: ferramentas de diagnóstico e de gestão. Porto Alegre: Artmed, 2008. p. 49-95.

BARDIN, L. Análise de conteúdo. Lisboa: Edições 70, 1977.
BECKER, B.E.; HUSELID, M.A.; ULRICH, D. Gestão estratégica de pessoas com scorecard: interligando pessoas, estratégia e performance. Rio de Janeiro: Campus, 2001.

CASADO, T. Comportamento organizacional: fundamentos para a gestão de pessoas. In: SANTOS, R.C. (Org.). Manual de gestão empresarial: conceitos e aplicações nas empresas brasileiras. São Paulo: Atlas, 2007. p. 212-233.

CHANG Jr., J. Gestão de pessoas através do desenvolvimento do comprometimento organizacional: uma abordagem holística e simultânea dos determinantes envolvidos nesse processo. 2001. 192f. Tese (Doutorado em Administração), Faculdade de Economia, Administração e Contabilidade, Universidade de São Paulo, (FEA/USP), São Paulo, 2001.

COOPER, D.R.; SCHINDLER, P.S. Métodos de pesquisa em administração. Porto Alegre: Bookman, 2003.

DAVEL, E.; VERGARA, S.C. (Orgs.). Gestão com pessoas e subjetividade. São Paulo: Atlas, 2001. 
DENZIN, N.K.; LINCOLN, Y.S. Collecting and interpreting qualitative materials. London: SAGE, 1998.

DENZIN, N.K.; LINCOLN, Y.S. Handbook of qualitative research. London: SAGE, 2000.

DESSLER, G. Conquistando comprometimento: como construir e manter uma força de trabalho competitiva. São Paulo: Makron Books, 1996.

EISENHARDT, K.M. Building theories from case study research. Academy of Management Review, v.14, n. 4, p. 532-550, 1989.

FLEURY, A.C.C.; FLEURY, M.T.L. Aprendizagem e inovação organizacional: as experiências de Japão, Coréia e Brasil. São Paulo: Atlas, 1997.

\section{HANDY, C.B. Como compreender as} organizações. Rio de Janeiro: Zahar, 1978.

HEILBRONER, R. A história do pensamento econômico. São Paulo: Nova Cultural, 1996. (Os Economistas).

MARCONI, M.A.; LAKATOS, E.M. Técnica de pesquisa. São Paulo: Atlas, 1982.

MASCARENHAS, A. O. Gestão estratégica de pessoas: evolução, teoria e crítica. São Paulo: Cengage Learning, 2008.

PEREIRA, O.G. Fundamentos de comportamento organizacional. Lisboa: Fundação Calouste Gulbenkian, 2004.

RICHARDSON, R. Pesquisa social: métodos e técnicas. São Paulo: Atlas, 1989.

ROBBINS, S.P. Comportamento organizacional. São Paulo: Prentice Hall, 2002.

ROBBINS, S.P. Comportamento organizacional. São Paulo: Pearson; Prentice Hall, 2005.

ROGERS, C.R. Sobre o poder pessoal. São Paulo: Martins Fontes, 1977.

SALANCIK, G. R. Commitment and the control of organizational behavior and belief. In: STAW, B. M.; SALANCIK, G. R. (Eds.). New direction in organizational behavior. Chicago: St.Clair, 1977. p. 1-54.

SCHEIN, E.H. Organizational culture and leadership. São Francisco: Jossey-Bass, 1987.
STACEY, R. The chaos frontier: creative strategic control for business. Oxford: Butter Worth Heineman, 1991.

WAGNER III, J.A.; HOLLENBECK, J.R. Comportamento organizacional: criando vantagem competitiva. São Paulo: Saraiva, 2003.

WALTON, E. R. Do controle ao comprometimento no local de trabalho. In: VROOM, V. H. Gestão de pessoas, não de pessoal: os melhores métodos de avaliação de desempenho. Rio de Janeiro: Campus, 1997. p. 95-112. (Série Harvard business review book).

ULRICH, D. Os campeões de recursos humanos: inovando para obter os melhores resultados. São Paulo: Futura, 1998.

VASCONCELOS, F.C. A institucionalização das estratégias de negócios: o caso das startups na internet brasileira em uma perspectiva construtivista. Revista de Administração Contemporânea - RAC, Curitiba, v. 8, n. 2, p. 159-179. 2004.

VASCONCELLOS, E.; HEMSLEY, J.R. Estrutura das organizações. São Paulo: Pioneira Thomson Learning, 2003.

VERGARA, S.C. Métodos de pesquisa em administração. São Paulo: Atlas, 2005.

YIN, R. Estudo de caso: planejamento e métodos. São Paulo: Bookman, 2005.

2001. 